Article

\title{
Microstructure and Properties of AA6061/SiCp Composites Sintered under Ultra High-Pressure
}

\author{
Lei $\mathrm{Xu}^{1,2, \dagger}{ }^{1}$, Erkuo Yang ${ }^{1, \dagger}$, Yasong Wang ${ }^{1}$, Changyun $\mathrm{Li}^{2, *}{ }^{-1}$, Zhiru Chen ${ }^{1}$ and Guofa Mi ${ }^{1, *}$ \\ 1 School of Materials Science and Engineering, Henan Polytechnic University, Jiaozuo 454000, China; \\ xulei@cupk.edu.cn (L.X.); 211806010014@home.hpu.edu.cn (E.Y.); 211706020012@home.hpu.edu.cn (Y.W.); \\ zhiru.chen@falcontech.com.cn (Z.C.) \\ 2 Faculty of Engineering, China University of Petroleum-Beijing at Karamay, Karamay 834000, China \\ * Correspondence: lichangyun@cupk.edu.cn (C.L.); peter@hpu.edu.cn (G.M.); Tel.: +86-099-0663-3341(C.L.); \\ +86-039-1398-7478 (G.M.) \\ $+\quad$ These authors contributed equally to this work and should be considered co-first authors.
}

Received: 3 September 2020; Accepted: 16 October 2020; Published: 21 October 2020

check for updates

\begin{abstract}
Ultra high-pressure sintering (UHPS) was used to prepare AA6061/SiCp composites with different contents and the effect of sintering temperatures on microstructure and mechanical properties was investigated in this study. The results showed that a uniform distribution of nano-SiC particles (N-SiCp) is obtained by the UHPS method. With the increase in N-SiCp contents, the higher hardness and better wear resistance could be inspected. The interfacial reactions and $\mathrm{Al}_{4} \mathrm{C}_{3}$ phase appeared above $550^{\circ} \mathrm{C}$. The relative density of composites first increased and then decreased; with the temperature raising it reached $99.58 \%$ at $600{ }^{\circ} \mathrm{C}$. The hardness and wear property showed the same trend with the hardness reaching $52 \mathrm{HRA}$ and wear rate being $1.0 \times 10^{-6} \mathrm{~g} / \mathrm{m}$ at $600{ }^{\circ} \mathrm{C}$. Besides, the wear mechanism of the composites is mainly composed of abrasive wear and adhesive wear.
\end{abstract}

Keywords: characterization; aluminum alloys; composites; powder methods; fracture behavior

\section{Introduction}

Al matrix composites reinforced by micron-sized particles can significantly improve the properties of materials, such as the hardness, wear-resistance, etc. [1-4]. However, the large size particles in composite materials may contribute to the appearance of holes around the reinforcement during the preparing process and will break or crack during service, reducing the mechanical properties of the composite. Thus N-SiCp is increasingly used as the reinforcement for composites. Commercial N-SiCp is mostly with irregular shapes, and hence, cracks occur at the sharp corners of the SiCp during the sintering process or service due to stress concentration. However, the N-SiCp prepared by high-energy ball milling is approximately spherical, which can significantly avoid the stress concentration and reduce the generation or propagation of cracks, resulting in the enhancement of the properties of composites. Although N-SiCp can improve the strength of the composite without reducing its plasticity in the related research [2-4] on $\mathrm{Al}$ matrix composites reinforced by $\mathrm{N}-\mathrm{SiCp}$, there are still some problems in the research of composites reinforced by nanoparticles due to the large specific surface area, easy agglomeration, and the low volume fraction of $\mathrm{N}-\mathrm{SiCp}$. Besides, the reinforcement particles are inclined to agglomerate and are not easy to sinter for the composite with the large volume fraction [5-8]. Chao [8] pointed out that the smaller $\mathrm{SiCp}$ represented the larger interface area between $\mathrm{SiC}$ and matrix in composite materials is, indicating an increased yield strength and tensile strength. Liu $[9,10]$ pointed out that $\mathrm{N}-\mathrm{SiCp}$ could make the yield strength and tensile strength of composites reach up to 102.5 and $175.0 \mathrm{mPa}$, respectively, leading to an augment of $50 \%$ and $30 \%$ than that of matrix alloy. Gao [11] pointed out that the grain size of the Al matrix composites reinforced by single N-SiCp could 
be significantly refined, showing an improved hardness and wear resistance. Zhang [12] prepared Al matrix composites reinforced by micron SiCp and N-SiCp through the stirring casting method. It was discovered that the nanoparticles can significantly improve the tensile strength and yield strength of the composites. Omyma et al. [13] also studied the hot-pressed sintered Al matrix composites reinforced by $\mathrm{N}-\mathrm{SiCp}$. The results showed that the hardness and compressive strength of composites reinforced by $\mathrm{N}-\mathrm{SiCp}$ were higher than that reinforced by micro-SiC at the same volume fraction. Besides, the grain refinement effect of $\mathrm{N}-\mathrm{SiCp}$ is significantly better than that of micron SiC.

In summary, researchers have gradually studied the effect of particle size on $\mathrm{Al}$ matrix composites from micron to single nanometer [14-16]. During the stirring casting process, matrix and reinforcement were mixed through mechanical stirring or magnetic stirring, followed by casting, which makes the $\mathrm{SiC}$ more easily agglomerated because of the large specific surface energy of the N-SiCp and the poor wettability between the reinforcement and matrix [17]. Although powder metallurgy combined with ball mill dispersion can reduce the agglomeration phenomenon, the sample with a low density and poor bonding is still prone to generating cracks. There are some certain disadvantages for the preparation methods with the low pressure in previous studies about $\mathrm{Al} / \mathrm{micro}-\mathrm{SiC}$ composites-for example, low density, low strength, shrinkage, and porosity due to the insufficient pressure $[14,16]$. Therefore, an effective preparation method is particularly important and in urgent need. UHPS, which is characterized by ultra-high-pressure during sintering, has received considerable attention over the past few years because it could solve the problem of the defects produced during conventional powder metallurgy techniques [18]. It was reported [19] that UHPS not only could improve the relative density of composites, but also delay the melting point, which could effectively inhibit the interface reaction. In this study, AA6061/N-SiCp composites were effectively prepared by UHPS above 1 GPa combined with ball milling (N-SiCp+AA6061 pre-dispersion). The effects of the volume fraction of N-SiCp and sintering temperature on the microstructure and mechanical properties of AA6061/N-SiCp composites were analyzed, aiming at the good sintering property.

\section{Materials and Experiments}

AA6061 alloy powders with an average size of 40 53 $\mu \mathrm{m}$ prepared by JW-25 vacuum metal atomization furnace (Chenhua Science Technology Corp., Ltd., Shanghai, China) were used as matrix material. The measured density and the purity are $2.65 \mathrm{~g} / \mathrm{cm}^{3}$ and $99.8 \%$, respectively, and have the color of silver gray, as shown in Figure 1. The N-SiCp, with an average size of $50 \mathrm{~nm}$, the density of $3.227 \mathrm{~g} / \mathrm{cm}^{3}$, gray-green color, ellipsoidal shape, purity of $99.9 \%$ and the specific surface area of $60 \mathrm{~m}^{2} / \mathrm{g}$, is depicted in Figure 2a. The N-SiCp were used as reinforcement and provided by Yaotian New Material Technology Co. Ltd. in Shanghai, China. The chemical compositions of the AA6061 are listed in Table 1. N-SiCp weighed in 1, 3, 5, 10, and 15 vol.\% were premixed with AA6061 alloy powder in a mortar and then milled into a high-speed vibrating ball mill (NanDa Instrument Plant, Nanjing, China). The mixing time and speed is $2 \mathrm{~h}, 300 \mathrm{r} / \mathrm{min}$, respectively. The mixed powders are shown in Figure $2 \mathrm{~b}$. To make N-SiCp distribute partly on the surface of the $\mathrm{Al}$ particles, the $\mathrm{Al}$ particles and the N-SiCp were mixed in a mortar according to the patent CN201210103182.6. The surface energy of the nanoparticles is high, and the coating layer improves the wettability of the material, hence it reduces the agglomeration of the $\mathrm{SiC}$ particles.

Table 1. Chemical component of AA6061 (wt $\%)$.

\begin{tabular}{ccccccccc}
\hline $\mathbf{S i}$ & $\mathbf{C u}$ & $\mathbf{M g}$ & $\mathbf{Z n}$ & $\mathbf{M n}$ & $\mathbf{T i}$ & $\mathbf{G r}$ & $\mathbf{F e}$ & Al \\
\hline 0.393 & 0.246 & 0.96 & 0.001 & 0.086 & 0.015 & 0.05 & 0.1 & balance \\
\hline
\end{tabular}




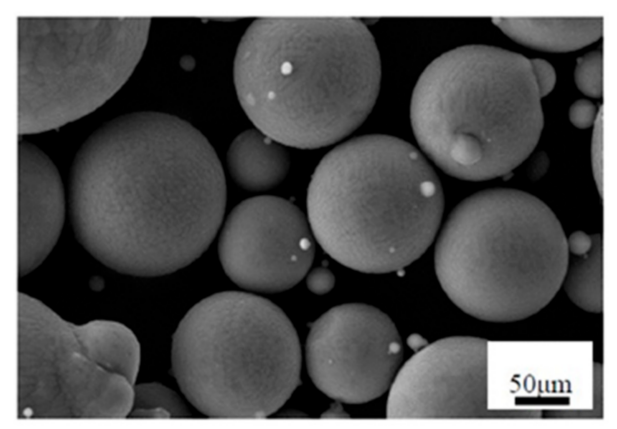

Figure 1. SEM morphology of AA6061 powder.

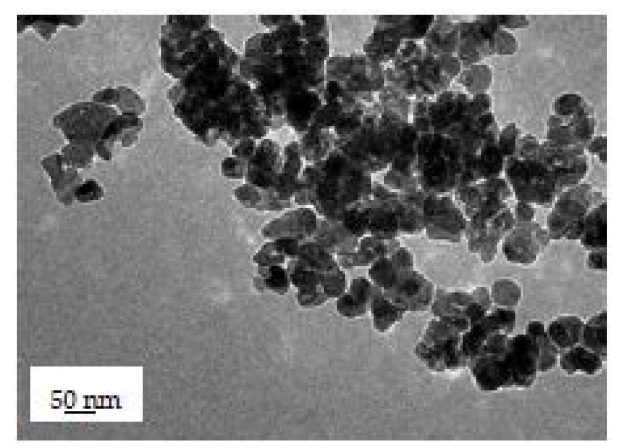

(a)

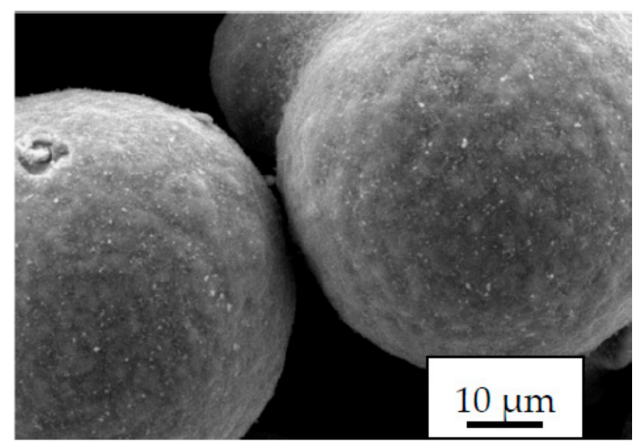

(b)

Figure 2. SEM micrographs of N-SiC powder (a) and AA6061/N-SiC powder mixture (b).

The $6 \mathrm{MK}-3 \mathrm{WY}-60$ six-face pressing machine was used as the sintering equipment. The powder is pre-compressed and then filled into the pyrophyllite block for sintering at $4.5 \mathrm{GPa}$, which is selected according to the experimental data, for $40 \mathrm{~min}$ and at $450,550,600$, and $650{ }^{\circ} \mathrm{C}$, respectively. The pressure was produced by a pressure cylinder, which is connected to a hinge. It uses oil pressure in the pipeline to generate high pressure, which is adjusted by the cross-sectional area. The pressure could be calculated according to Equation (1). $\mathrm{P}_{1}, \mathrm{P}, \mathrm{S}_{1}, \mathrm{~S}$, stands for the pressure generated by a pressure cylinder, the pressure applied to the sample, the cross-sectional area of the hammer, the area contacted between the sample, and the hammer, respectively. An optical microscope (OM, Olympus GX-51, Tokyo, Japan) and a field emission scanning electron microscope (SEM, Merlin Compact, Carl Zeiss NTS GmbH, Jena, Germany) were used for microstructure characterization of the polished specimens. An X-ray diffractometer (XRD, SmartLab, Rigaku Corporation, Tokyo, Japan) was used for phase analysis using $\mathrm{CuK} \alpha$ radiation in the step scan mode and with the scanning speed of $10^{\circ} / \mathrm{min}$. The interface microstructure was characterized using a high-resolution transmission electron microscope (TEM, JEM-2100, JEOL Ltd., Tokyo, Japan). The density was measured by the Archimedes method using the density tester (ED-300C, TecFront Electronics Corp., Shanghai, China). The hardness was measured by a Rockwell hardness tester (HBE-300, Wobot Measuring Instruments Co., Ltd, Shanghai, China), under the load of $50 \mathrm{Kgf}$ for $10 \mathrm{~s}$. The wear tests were conducted by a wear tester (M-2000, Hongda Testing Instrument Co. Ltd., Jinan, China). Every test was repeated three times to check the reproducibility and the reliability of the results.

$$
\mathrm{P}=\mathrm{P}_{1} \mathrm{~S}_{1} / \mathrm{S}
$$

\section{Results and Discussion}

\subsection{Effect of the Volume Fractions of N-SiCp on Microstructure and Interface}

Figure 3 shows the microstructures of the composites with 1, 3, 10, 15 vol.\% N-SiCp sintered at $550{ }^{\circ} \mathrm{C}$ under the compacting pressure of 4.5 GP. As shown in Figure 3a,b, Al particles without the agglomerations are uniformly coated with a small layer of the N-SiCp. There are uniform grains 
with a small difference and smooth grain boundaries. The particles change from a hexagon shape in Figure $3 \mathrm{a}-\mathrm{d}$ to more circular shapes in Figure $3 \mathrm{e}$ at $4.5 \mathrm{GPa}$. Increasing the volume fraction of the $\mathrm{N}-\mathrm{SiCp}$, agglomeration appears at the boundary of the matrix in Figure $3 \mathrm{c}, \mathrm{d}$ and the roundness of the Al particles increases gradually from an irregular polygon to a circular shape, as shown in Figure $3 e$. During the process of UHPS, the Al particle is pressed and deformed with each other. As the volume fraction of the N-SiCp increases, the N-SiCp particles surrounded by the Al particles begin to withstand the certain sintering pressure, resulting in the Al particles retaining a good roundness [20]. Besides, as the content of the N-SiCp continues to rise, the particle becomes uneven and increasingly small. During the sintering process, the pores between the particles will diffuse and migrate to the boundary of the matrix, and the small pores merge into the large pores, which make the pores disappear, and the volume of the Al particles becomes smaller.

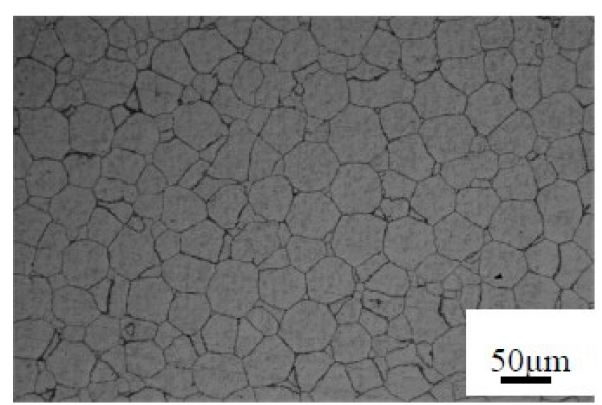

(a)

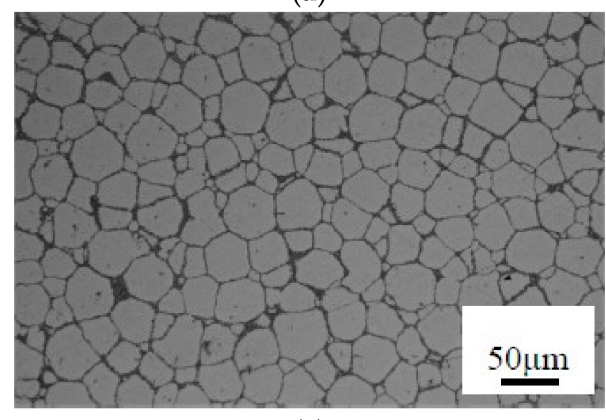

(c)

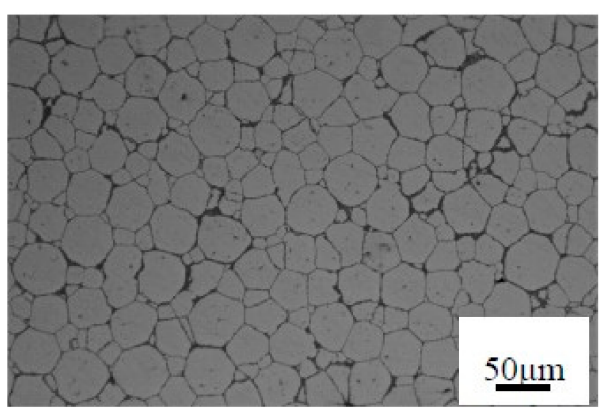

(b)

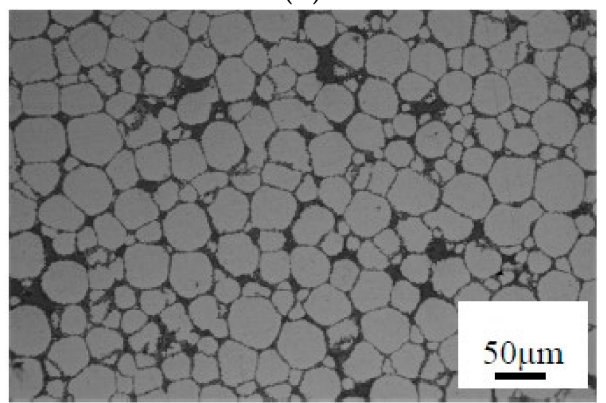

(d)

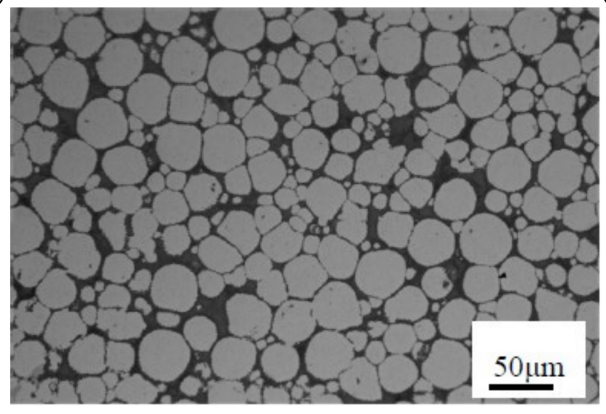

(e)

Figure 3. OM micrograph of AA6061/N-SiCp composites sintered at $550^{\circ} \mathrm{C}$ with 1 (a), 3 (b), 5 (c), 10 (d) and 15 (e) vol.\% N-SiCp.

Figure 4 presents a high-magnification microstructure of AA6061/N-SiCp sintered at $4.5 \mathrm{GPa}$ and $550{ }^{\circ} \mathrm{C}$ with different contents of N-SiCp particles. As shown in Figure 4a for AA6061/3 vol.\% $\mathrm{N}-\mathrm{SiCp}, \mathrm{N}-\mathrm{SiCp}$ lined at the grain boundary of $\mathrm{Al}$ particles. What is more, the discontinuous short rod phase (off-white color) appears at the boundaries of Al particles in Figure 4c. The EDS point of Area 1 in Figure 4c is analyzed for the phase, as shown in Figure 5a. The elemental content of this point was obtained from the EDS point analysis. Based on the elemental content, the bulk composition could be judged roughly in the first step. The main elements are $\mathrm{Al}$ and $\mathrm{O}$, and the $\mathrm{C}$ element is 
relatively low, which was obtained from Figure 5a. Depending on the element content, it can be judged that the bulk phase is $\mathrm{Al}_{4} \mathrm{C}_{3}$ or $\mathrm{Al}_{2} \mathrm{O}_{3}$. The line scan analysis of Area 2 in Figure $4 \mathrm{~d}$ is shown in Figure $5 \mathrm{~b}$. The $\mathrm{C}$ element and the $\mathrm{O}$ element is relatively stable throughout the whole scanning distance. Al content begins to reduce at the intersection of $\mathrm{SiC}$ and $\mathrm{Al}$ when scanning distance is about $6 \mu \mathrm{m}$. In comparison, Si content presents an increasing trend. The lowest $\mathrm{Al}$ content could be found at approximately $7.5 \mu \mathrm{m}$ distance and the infiltration zone lasts for $1 \mu \mathrm{m}$. Similarly, an elemental interpretation zone of about $0.8 \mu \mathrm{m}$ appears on the other side at $13 \mu \mathrm{m}$. The interdiffusion of the elements promotes the reaction between the elements in the interface region, causing the formation of compounds. However, the bonding strength increases when the amount of $\mathrm{Al}_{4} \mathrm{C}_{3}$ is small. When the amount of $\mathrm{Al}_{4} \mathrm{C}_{3}$ reaches a critical value, the interface will be damaged. The influence of the specific product content on the properties of the composite material has not been specifically reported before.

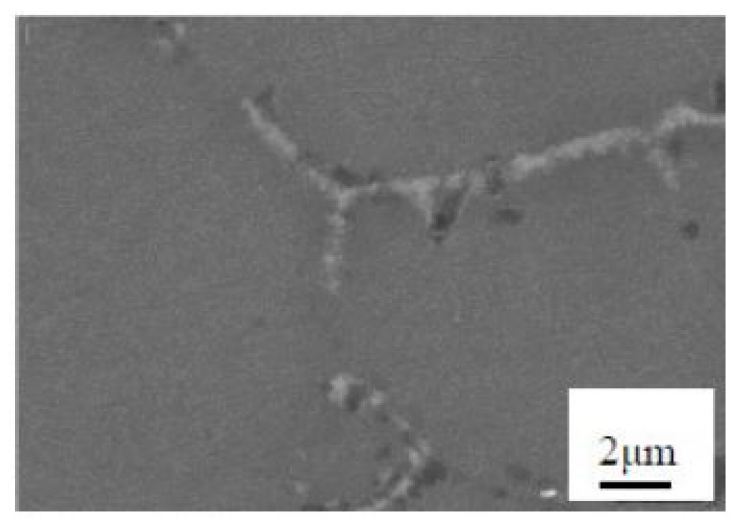

(a)

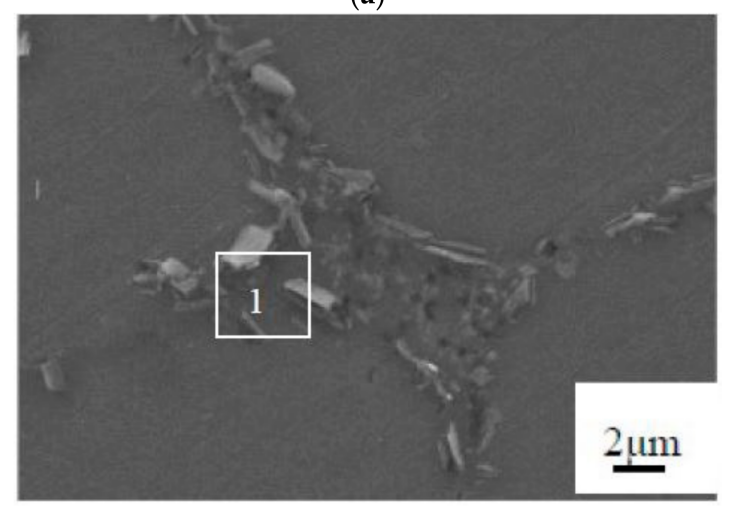

(c)

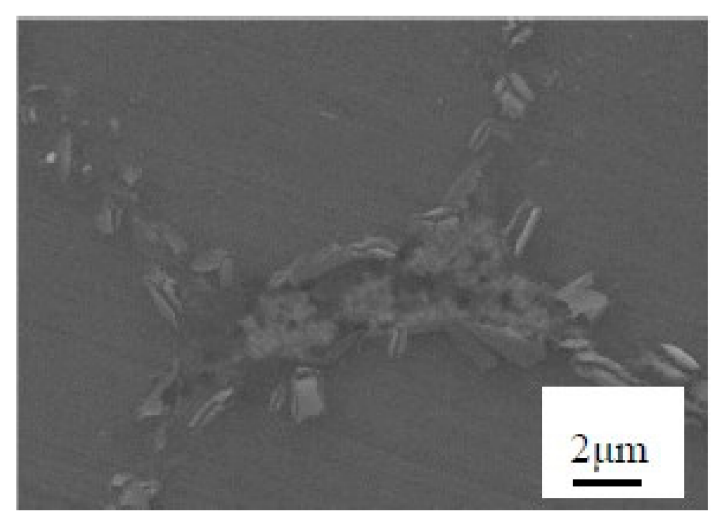

(b)

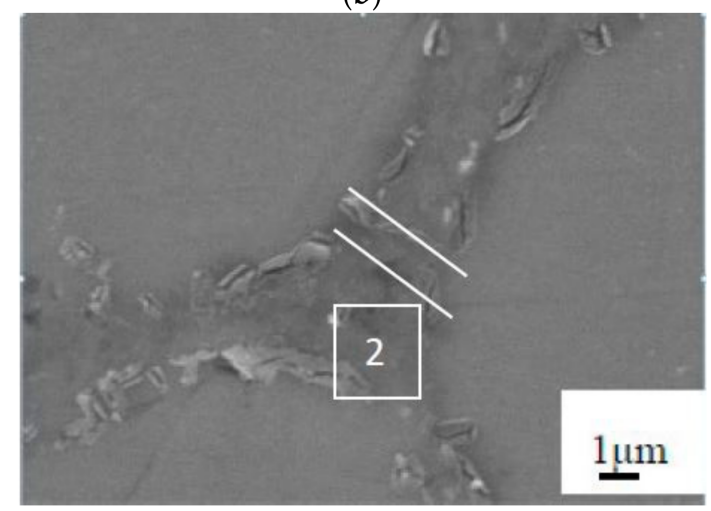

(d)

Figure 4. SEM micrographs of AA6061/N-SiC composites sintered at $550^{\circ} \mathrm{C}$ with 3 (a), 5 (b), 10 (c) and 15 (d) vol.\% N-SiCp.

To further determine the composition of the phase, $\mathrm{X}$-ray diffraction was used to examine the constituents of the AA6061/N-SiCp composites with different volume fractions of N-SiCp, as shown in Figure 6. With the increase in $\mathrm{SiCp}$ content, the peak intensity of $\mathrm{SiC}$ gradually increases at $32^{\circ}$. For AA6061/5 vol. $\% \mathrm{~N}-\mathrm{SiCp}$, the two main peaks of the $\mathrm{Al}_{4} \mathrm{C}_{3}$ phase are detected at $2 \theta$ of $31^{\circ} \sim 32^{\circ}$ while the peak is not detected for the sample with 1 or 3 vol.\% N-SiCp. Combined with the SEM micrograph of AA6061/3 vol.\% N-SiCp, a short rod-like phase appears at a certain position. The larger volume fraction of $\mathrm{N}-\mathrm{SiCp}$ content is, the more $\mathrm{N}-\mathrm{SiCp}$ around the $\mathrm{Al}$ particles, and the larger the interface surface exists between N-SiCp and Al particles. Moreover, the probability of reaction will increase, resulting in more product. 


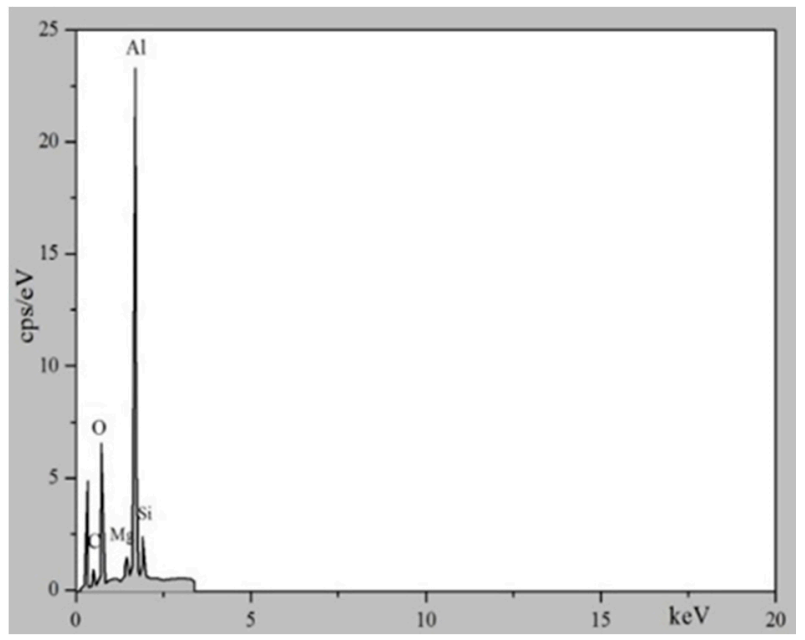

(a)

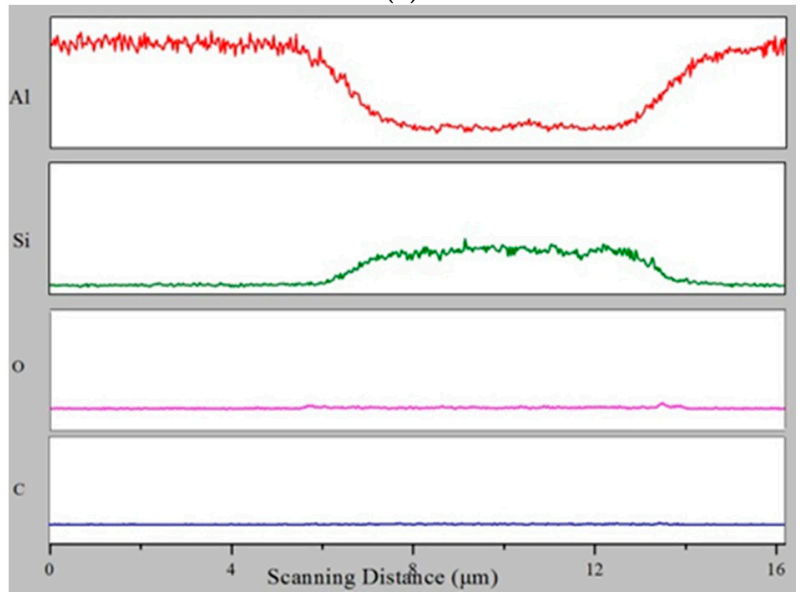

(b)

Figure 5. EDS-SEM analysis: (a) The analysis of point 1 of AA6061/10 vol.\% N-SiC, (b) The analysis of line scanning 2 of AA6061/15 vol.\% N-SiC sintered at $550{ }^{\circ} \mathrm{C}$.

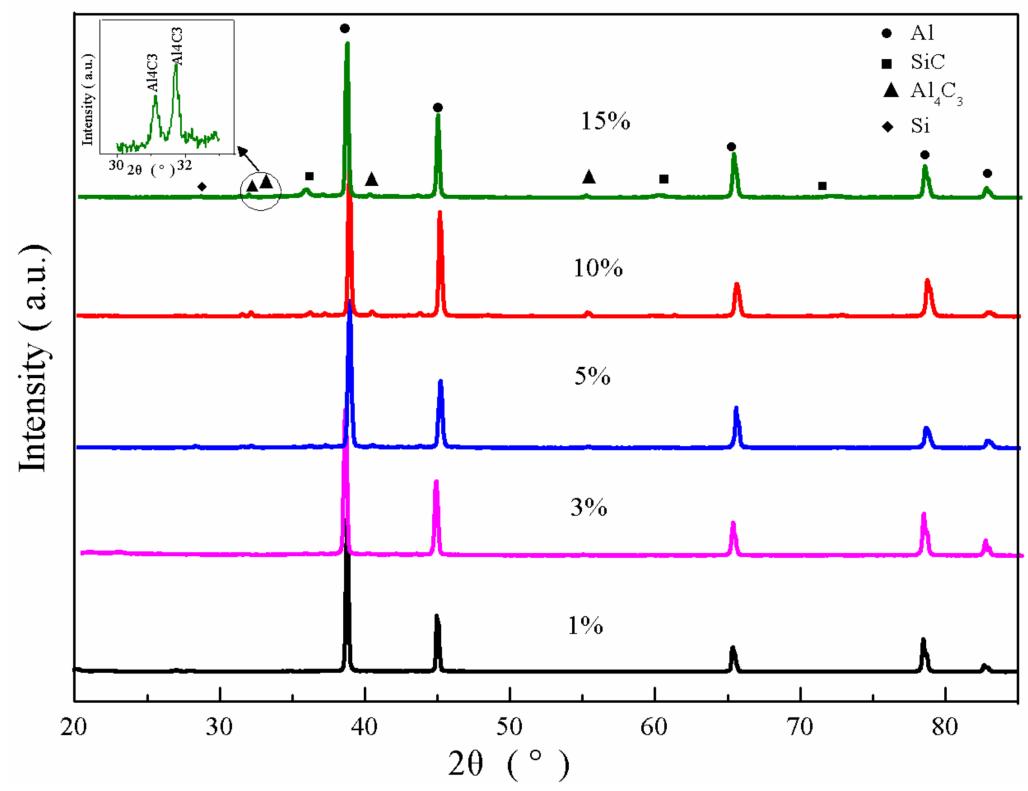

Figure 6. XRD diffraction pattern of AA6061/N-SiCp sintered at $4.5 \mathrm{GPa}$ and $550{ }^{\circ} \mathrm{C}$ with different content of N-SiCp particles. 
Figure 7a shows the TEM micrographs of AA6061/1 vol.\% N-SiCp. Figure $7 \mathrm{~b}$ shows the high-resolution microstructure of the interface in Figure 7a. The dark gray ellipsoidal particles in Figure $7 \mathrm{a}$ are $\mathrm{N}-\mathrm{SiC}$ particles with a size of $50 \mathrm{~nm}$, and the white edge is the Al matrix. The interface of the AA6061/1 vol.\% N-SiCp is clean and combined tightly and continuously. Figure 7c shows an inverse Fourier transform diagram of the high-resolution map of the $C$ region in Figure $8 \mathrm{~b}$. There are many dislocations near the N-SiCp interface. There usually exist thermal misfit dislocations at the interface due to the difference in the thermal expansion coefficient during sintering and cooling. Miller and Humphrey [21] derived the formula of the dislocation density increment for the ideal cubic shape reinforcement particle composite:

$$
\Delta \rho=12 \Delta \alpha \Delta T V_{P} / B D
$$

where $\Delta \alpha$ and $\Delta T$ are the difference in thermal expansion coefficient between the reinforcement and the matrix and the temperature difference between the sintering temperature and room temperature, respectively. $B$ means Berner vector, which could be determined by the Berner loop of the dislocation, the Berner vector of the dislocation loop, or half-dislocation loop, which is relatively complicated [22]. $D$ and $V_{p}$ are the average sizes of the reinforcement particles and the volume fraction of the reinforcement, respectively.

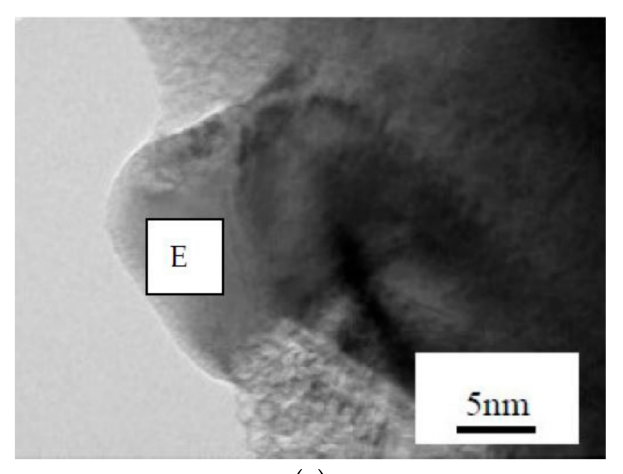

(a)

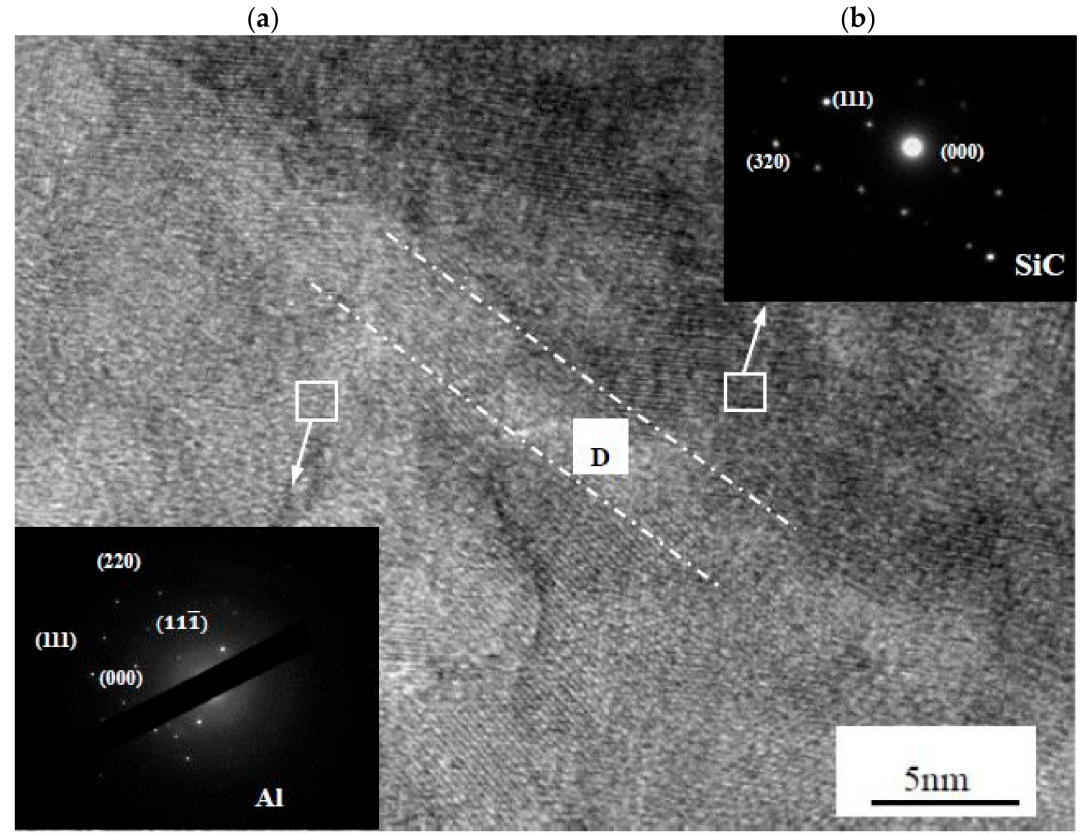

(c)

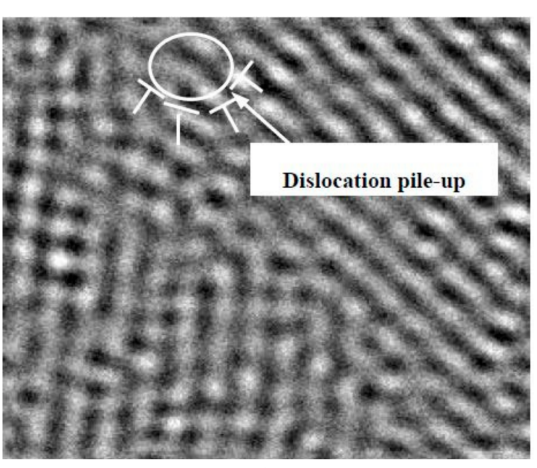




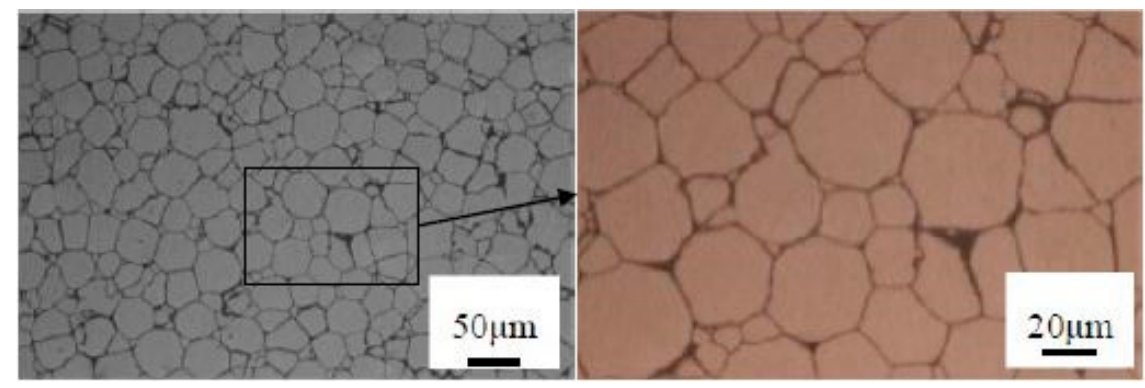

(a)

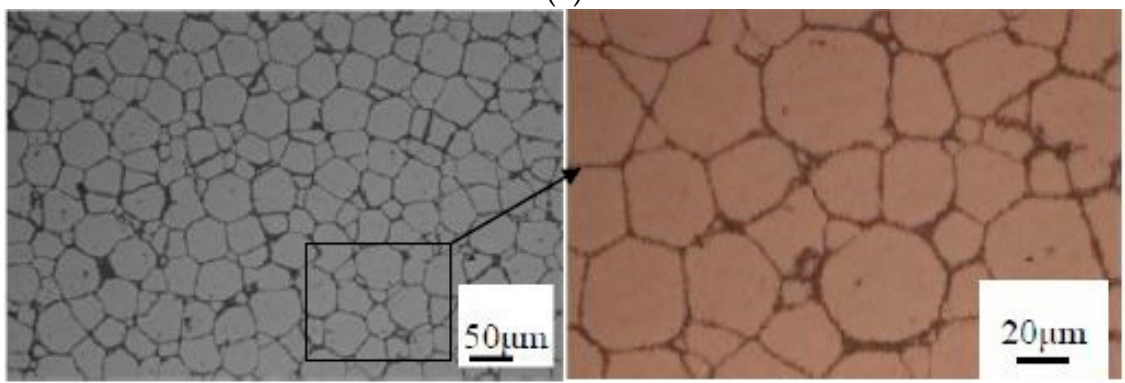

(b)

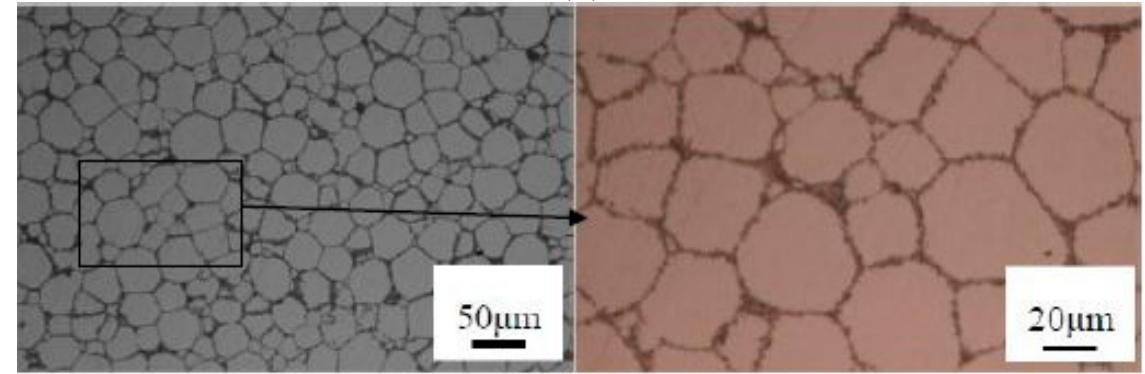

(c)

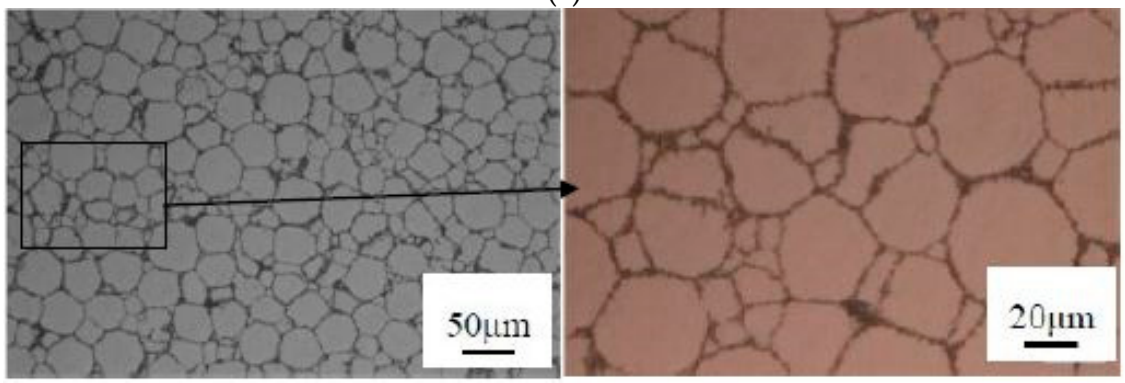

(d)

Figure 8. OM micrograph of AA6061/5 vol.\% N-SiC composites sintered at 450 (a), 550 (b), 600 (c), $650\left(\right.$ d) ${ }^{\circ} \mathrm{C}$.

Equation (2) illustrates that the dislocation density is related to the thermal expansion coefficient of the reinforcement material and the matrix material, the sintering temperature, the size and volume fraction of the reinforcement particles. The smaller the reinforcement is, the larger dislocation densities that can be obtained. Furthermore, increased dislocation density can also improve the strength of the material. 


\subsection{Effect of the Sintering Temperature on Microstructure and Interface}

The samples in this work were fabricated by UHPS method. In this case, the sintering temperature is different from that under normal pressure conditions. Under UHSP conditions, the melting point increase with the pressure rising, according to the Simon-Glatzel Equation (3) [23]

$$
T_{m}=T_{\mathrm{m}_{0}}(\mathrm{P} /(A+1))^{B}
$$

where $\mathrm{P}$ is pressure in GPa and $T_{\mathrm{m} 0}$ is melting temperature in Kelvin at $100 \mathrm{kPa}$. Therefore, it plays a great role in melting. Yuan [24] prepared AA6061/30 vol.\% N-SiCp composite by hot pressing sintering in vacuum at $540,560,580,600,650{ }^{\circ} \mathrm{C}$, and $70 \mathrm{mPa}$, respectively. At $540{ }^{\circ} \mathrm{C}, \mathrm{SiC}$ particles agglomerated in the microstructure of composite material, resulting in more obvious voids between each other. As the temperature increases, the voids between the $\mathrm{SiC}$ particles became fewer, and there were no large voids in the matrix. At $600{ }^{\circ} \mathrm{C}$, the $\mathrm{SiC}$ particles were filled with the $\mathrm{Al}$ matrix, and no reinforcement voids appeared, suggesting that the interface bonding is good. $\mathrm{Li}$ et al. [25] prepared an $\mathrm{Al} / \mathrm{SiC}$ powder mixture by high energy ball milling and sintered it by spark plasma sintering at $540{ }^{\circ} \mathrm{C}$ and $40 \mathrm{mPa}$. From the perspective of the microstructure, the overall distribution of $\mathrm{SiC}$ particles is uniform in the $\mathrm{Al} / \mathrm{SiCp}$ composite. For the same content of $\mathrm{SiC}$ particles, the agglomerations of nano-scale $\mathrm{Al} / \mathrm{SiC}$ composites are more common and serious than those of micro-scale $\mathrm{Al} / \mathrm{SiC}$ composites. For the same size of $\mathrm{SiC}$ particles, the $\mathrm{Al} / \mathrm{SiC}$ composites show more agglomeration as the $\mathrm{SiC}$ content increases.

Figure 8 presents the microstructure of AA6061/5 vol. $\%$ N-SiCp composites sintered at different temperatures at $4.5 \mathrm{GPa}$. It seems that, as the temperature increases, the composite has a slight agglomeration of $\mathrm{N}-\mathrm{SiCp}$. The boundary between the $\mathrm{Al}$ particles and the $\mathrm{N}-\mathrm{SiCp}$ layer is smooth at $450{ }^{\circ} \mathrm{C}$ as indicated in Figure 8a. However, from the enlarged figure in Figure $8 \mathrm{~b}-\mathrm{d}$, as the temperature rises, some glitch from the interface to the $\mathrm{Al}$ particles, indicating that the particles extend from the boundary to the $\mathrm{Al}$ particles on both sides, which makes the boundary rough. Additionally, an increasing number of small size particles could be inspected. Because of the low temperature, there are a large number of connected pores between the Al particles or between the N-SiCp, and between the Al particle and N-SiCp. These small pores could diffuse on the sample surface. Due to the continuous reduction and disappearance, the micropores begin to increase, and the similar small pores can be merged by the micropores. This will contribute to the reduction in the total pores and the volume fraction of the composite, as well as the increases in the density. As the temperature further increases, the pore surface becomes smooth and begins to round, but the pores do not reduce or disappear. At this time, under the action of the pressure, the pores move toward the surface of the $\mathrm{Al}$ particles, and the atoms in the $\mathrm{Al}$ particles move in the opposite direction. The pores are filled and grown into smaller $\mathrm{Al}$ particles, illustrating the increment of small-sized particles in the metallographic photograph.

Figure 9 shows the high-magnification microstructure of AA6061/5 vol. $\%$ N-SiCp composites at different sintering temperatures and $4.5 \mathrm{GPa}$. Judging from the microstructure at $450{ }^{\circ} \mathrm{C}$ in Figure $9 \mathrm{a}$, the boundary between the particles is relatively smooth. The granules begin to appear at $550{ }^{\circ} \mathrm{C}$, as shown in Figure $9 \mathrm{~b}$. The increasing temperature could provide more energy required for the reaction, so the particles tend to grow, as shown in Figure 9d. To determine the phase at the boundary, the XRD analysis was performed on the sample. As shown in Figure 10, the diffraction angle $2 \theta$ was partially magnified from $30^{\circ}$ to $32.5^{\circ}$. It was observed that no diffraction peak appeared at $450{ }^{\circ} \mathrm{C}$. The diffraction peaks appeared at 550,600 , and $650{ }^{\circ} \mathrm{C}$. The diffraction peak is mainly composed of the $\mathrm{Al}_{4} \mathrm{C}_{3}$ phase, indicating that the temperature has a significant effect on the interfacial reaction of $\mathrm{Al} / \mathrm{N}-\mathrm{SiCp}$ composites. 


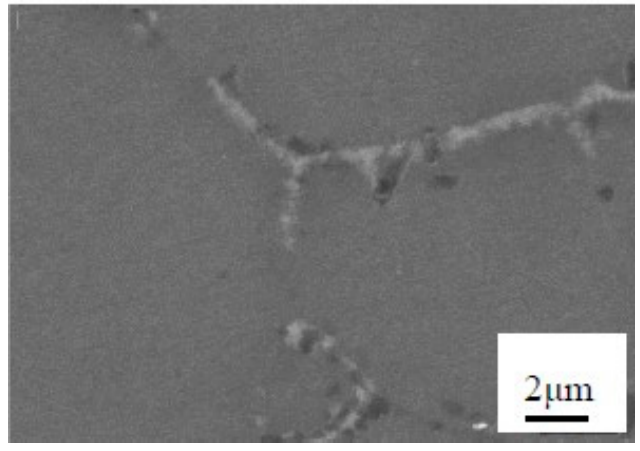

(a)

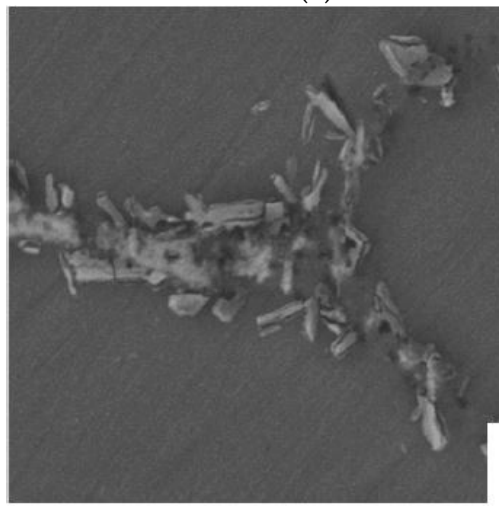

(c)

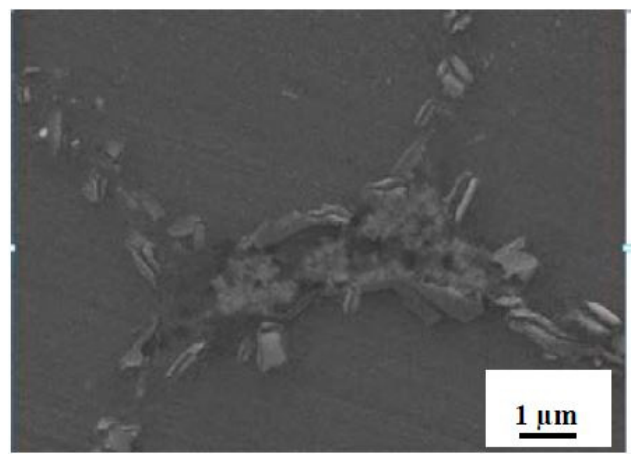

(b)

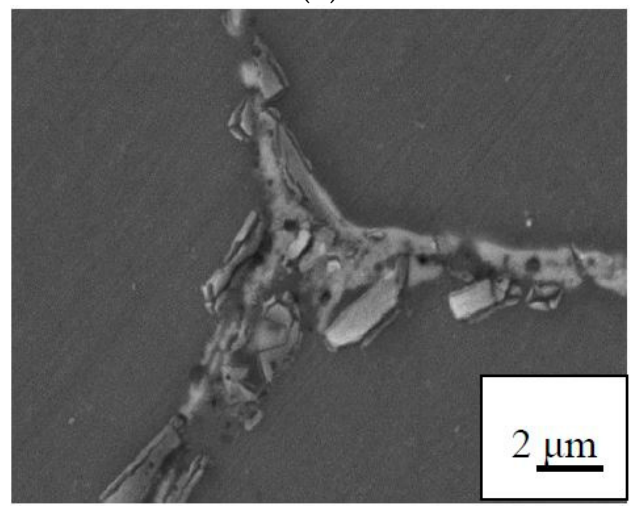

(d)

Figure 9. SEM micrographs of AA6061/5 vol.\% N-SiC composites sintered at 450 (a), 550 (b), 600 (c) and $650(\mathbf{d}){ }^{\circ} \mathrm{C}$.

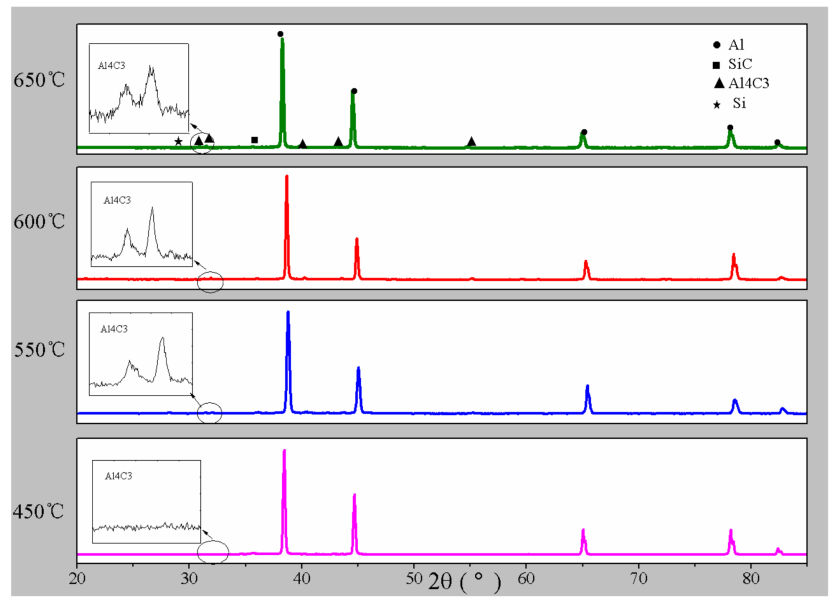

Figure 10. XRD patterns of AA6061/5 vol.\% N-SiCp sintered at different temperatures: 450, 550, 600, and $650{ }^{\circ} \mathrm{C}$.

\subsection{Evolution Law of Density of Composite Materials}

Figure 11 shows the density tendency of AA6061/N-SiCp composite. Figure 11a shows a variation trend of the composite density with volume fraction at $4.5 \mathrm{GPa}$ and $550{ }^{\circ} \mathrm{C}$. It can be seen that the density gradually decreases as the volume fraction of SiCp increases. The density of pure AA6061 reaches $99.38 \%$. For AA6061/1.0 vol.\% N-SiCp, the density decreases to about $98 \%$. At this time, the content of $\mathrm{N}-\mathrm{SiCp}$ is relatively small, and there is no obvious agglomeration. For the small amount of $\mathrm{N}-\mathrm{SiCp}$ around the $\mathrm{Al}$ matrix, the UHSP causes the $\mathrm{Al}$ particles to become irregular, and the contact area between particles increases, thereby promoting the diffusion of the elements and leading to the 
large density of the material. When the volume fraction is increased to $15 \mathrm{vol} . \%$, the density drops to about $95 \%$. In this condition, more agglomeration of the N-SiC could be discovered in the composites. Due to the small self-diffusion coefficient of $\mathrm{SiC}$, and poor ability of sintering, the sintered material seldom achieves full densification. The sintering temperature of the $\mathrm{SiC}$ ceramic at normal pressure is as high as $2000{ }^{\circ} \mathrm{C}$, and the density is only $96 \%$. After being sintered at $4.5 \mathrm{GPa}$ and $1300{ }^{\circ} \mathrm{C}$ by UHSP, the density of the SiC reported by Xie [26] can just reach 93\%. Although UHSP can improve the densification of $\mathrm{SiC}$, to some extent, the volume shrinkage between $\mathrm{SiCp}$ is small, and the density cannot reach that of pure Al. Therefore, the larger the volume fraction of N-SiCp is, the smaller the volume shrinkage is during sintering. The small pores between the particles reduce the density of the material.

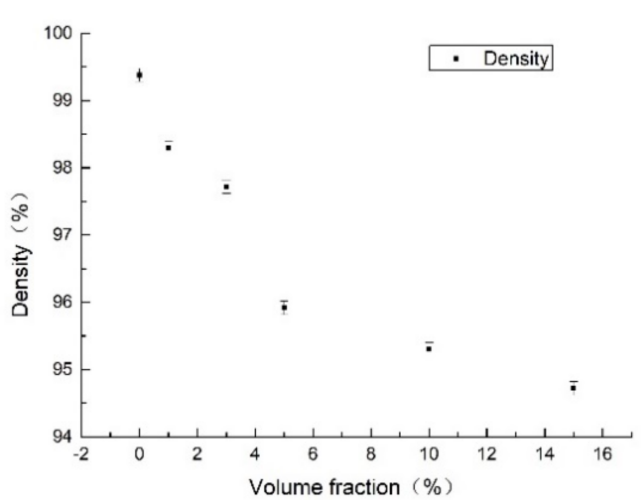

(a)

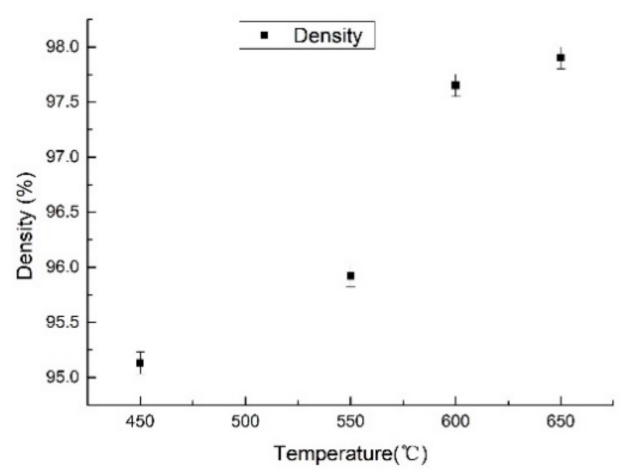

(b)

Figure 11. The curve of the relative density of AA6061/N-SiCp composite: Relationship between relative density and volume fraction for AA6061/5 vol.\% N-SiCp sample (a). Relationship between relative density and sintering temperature at $4.5 \mathrm{GPa}$ for AA6061/5 vol. $\% \mathrm{~N}-\mathrm{SiCp}$ sample (b).

Figure $11 \mathrm{~b}$ draws the density variation of AA6061/5 vol.\% N-SiCp composites sintered at different temperatures and $4.5 \mathrm{GPa}$. As the temperature increases, the density of the composite rises gradually. The density is $98 \%$ at $650{ }^{\circ} \mathrm{C}$. Ultrahigh pressure could promote the plastic flow of the $\mathrm{Al}$ matrix. The higher temperature usually represents the better plastic flow, more volumetric shrinkage, and higher density of the material. Combined with the analysis of the microstructure of the material in Section 3.1, due to the high-temperature effect, the internal atoms of the $\mathrm{Al}$ matrix migrate to the large pores formed at the initial stage of sintering, and the filled pores could further increase the density.

\subsection{Evolution of Hardness}

Figure 12 shows the hardness variation of the AA6061/N-SiCp composite. Figure 12a shows the hardness variation curve at $4.5 \mathrm{GPa}$ and $550{ }^{\circ} \mathrm{C}$. It can be seen that the hardness gradually increases with the addition of the N-SiCp. The hardness of the AA6061/15vol.\% N-SiCp reached up to 48.3 HRA, which was $52.8 \%$ higher than that of pure AA6061. For the AA6061/N-SiCp composite, the higher content of N-SiCp can lead to better deformation resistance of the SiC. When the indenter contacts the surface, the higher hardness of the composite could be found. When the volume fraction is high, despite there being many agglomerations in the material interior, the distance among the nanoparticles is very small, therefore the agglomeration has the same bearing capacity for the indenter load. It can be seen from Figure 12b that the hardness of the AA6061/5 vol.\% N-SiCp increases with the augment of the temperature at $4.5 \mathrm{GPa}$. With the temperature increasing, small-sized Al particles crowd more tightly in the microstructure and the interfacial area between N-SiCp and Al matrix increases. It can improve the dispersion uniformity of $\mathrm{SiC}$, dispersion strengthening effect, and the hardness value. 
However, the hardness is slightly decreased at $650{ }^{\circ} \mathrm{C}$. According to the microstructure analysis in Section 3.1, the $\mathrm{SiC}$ can react with the $\mathrm{Al}$ substrate at $650^{\circ} \mathrm{C}$ according to the following reaction:

$$
4 \mathrm{Al}+3 \mathrm{SiC} \rightarrow \mathrm{Al}_{4} \mathrm{C}_{3}+3 \mathrm{Si}
$$

The reaction is controlled by a dissolution-diffusion mechanism [27]. The $\mathrm{Al}_{4} \mathrm{C}_{3}$ phase is an excessive brittle phase which reduces the interfacial bonding strength between $\mathrm{SiC}$ reinforcement and Al matrix. Correspondingly, the mechanical properties are degraded. When the indenter is pressed into the surface, the ability to transfer the load at the interface is lowered, thereby lowering the hardness.

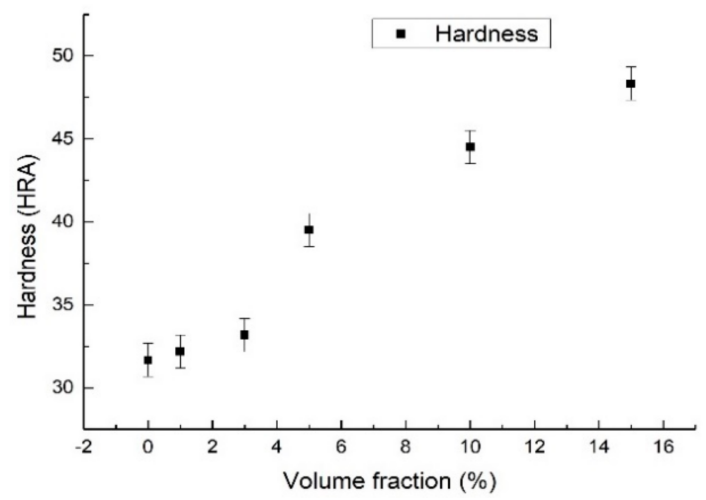

(a)

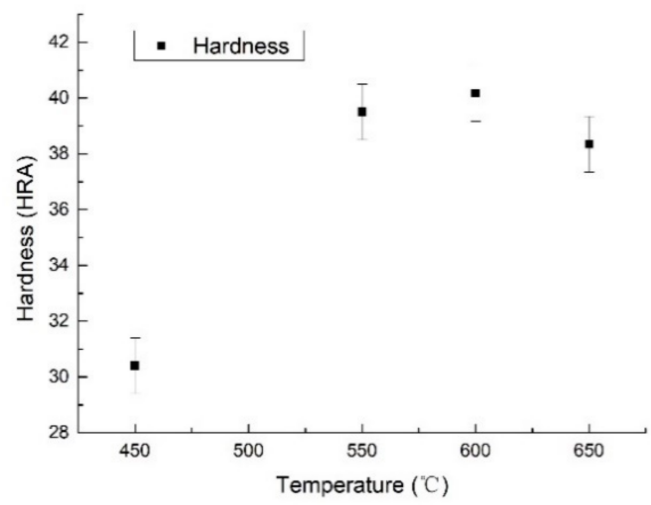

(b)

Figure 12. The curve of the hardness of AA6061/N-SiCp composite at $4.5 \mathrm{GPa}$ : Relationship between hardness and volume fraction: 0, 1, 3, 5, 10, 15 vol.\% (a), Relationship between hardness and sintering temperature: $450,550,600,650{ }^{\circ} \mathrm{C}(\mathbf{b})$ for AA6061/5 vol. $\%$ N-SiCp sample.

\subsection{Research on Mechanical Property}

Some of the literature [27-32] studied the tensile strength of Al/N-SiCp composites with the different content of SiCp. In this paper, AA6061/N-SiCp composites with 3, 5, and 10 vol.\% were prepared at $550^{\circ} \mathrm{C}$. It showed the largest tensile strength of the composite, $314.7 \mathrm{MPa}$ for AA6061/3 vol.\% $\mathrm{N}-\mathrm{SiCp}$ without further treatment. Compared with the AA6061/N-SiCp prepared by powder metallurgy at $600{ }^{\circ} \mathrm{C}$, the tensile strength increased by about $88.2 \%$. The fracture morphology is shown in Figure 13 . The surface of the port has a stone-like fracture morphology, which is due to the dispersion of N-SiCp at the grain boundary. The dispersion of $\mathrm{N}-\mathrm{SiCp}$ forms a large number of fine dimples distributed along the grain boundary. The N-SiCp location is inclined to cause stress concentration, and thus the crack is easy to form at the grain boundary and expands along the grain boundary, resulting in brittle grain boundary fracture. Therefore, the fracture mechanism is an intergranular fracture.

Predecessors [28-35] studied the different $\mathrm{Al} / \mathrm{SiCp}$ composites with different particle sizes and sintered them at different temperatures. The tensile properties of the $\mathrm{Al} / \mathrm{SiC}$ matrix composites make a difference at various temperatures.

In this study, AA6061/5 vol. $\% \mathrm{~N}-\mathrm{SiCp}$ composites were sintered at 450,550 , and $600{ }^{\circ} \mathrm{C}$, respectively. The highest tensile strength of the composite was obtained at $550{ }^{\circ} \mathrm{C}$, which was about $227 \mathrm{MPa}$. The fracture morphologies of sample sintered at different temperatures are shown in Figure 14. Figure 14a shows the fracture morphology of AA6061/5 vol.\% N-SiCp composites. The fracture mode is similar to that of intergranular fracture. The irregularity in this figure is attributed to the AA6061 particles, which are pressed against each other under UHPS, and are changed from spherical particles to polyhedral shapes. The material fracture first occurs at the sintered neck between the particles. The micro-oxidation of the impurities on Al particles causes the performance of the sintered neck to reduce, corresponding to the internal grain boundary of the material. Thereby, it causes fracture from the neck and leads to intergranular fracture. 

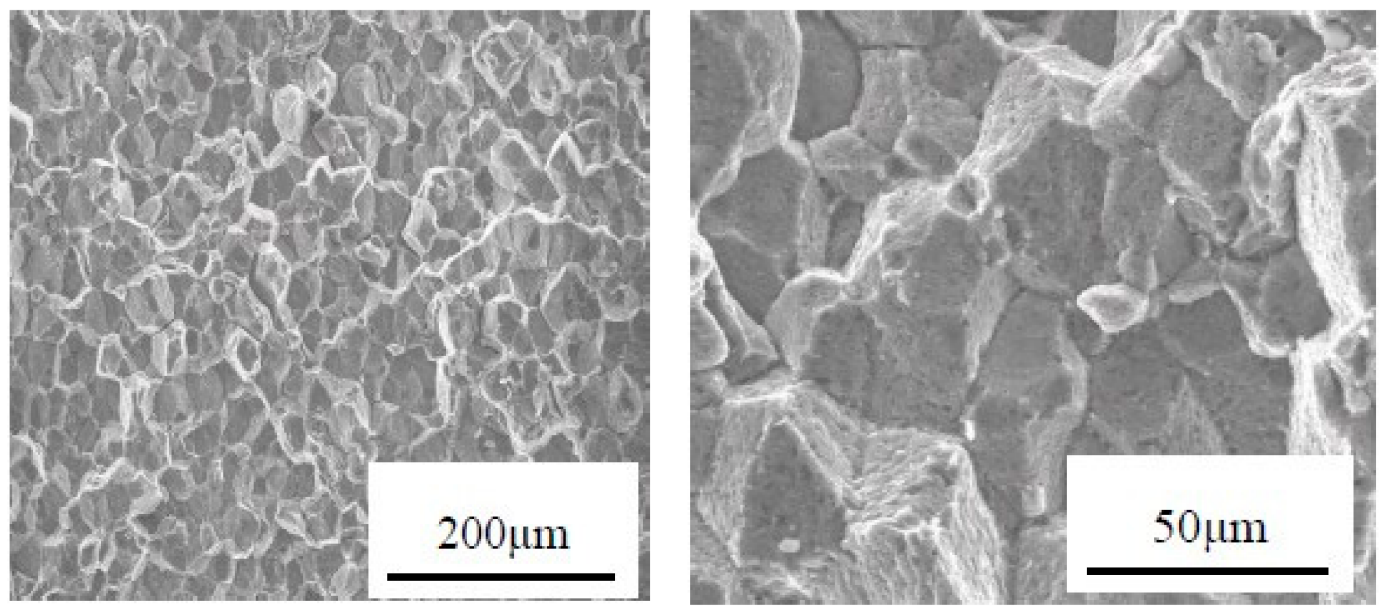

Figure 13. Fracture morphology of AA6061/3 vol. $\%$ N-SiCp composite sintered at $550{ }^{\circ} \mathrm{C}$.

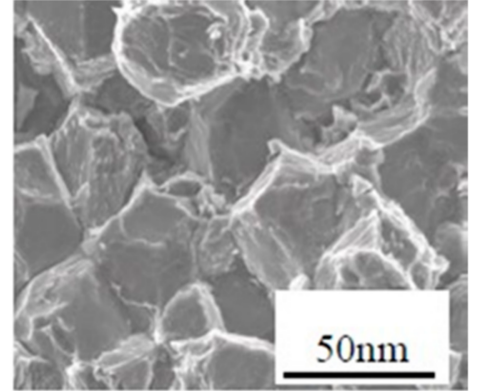

(a)

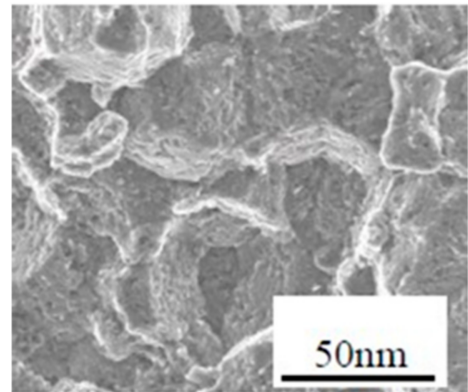

(b)

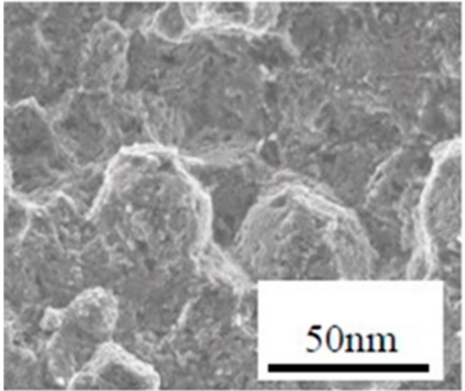

(c)

Figure 14. SEM micrograph of the fracture surface of AA6061/5 vol.\% N-SiCp composites produced sintered at 450 (a), $550(\mathbf{b}), 600{ }^{\circ} \mathrm{C}$ (c), respectively.

Figure 14b shows the fracture morphology of AA6061/5 vol.\% N-SiCp composites prepared at $4.5 \mathrm{GPa}$ and $550{ }^{\circ} \mathrm{C}$. The fracture mechanism is a quasi-cleavage fracture, and there is a flat "cleavage-like" region in the figure. The small plane and micropores appear. The sample of Figure 14b is similar to the sample in Figure 14a. Increasing the temperature is more conducive to the elimination of voids and defects so that the sintered neck with excellent performance is formed between the AA6061 particles. The fracture morphology in Figure 14b has a great difference from that in Figure 14a. During the tensile process, the AA6061 matrix is plastically deformed, but N-SiCp distributed among them are small. The uncoordinated deformation causes micro-voids to occur in the small range, which nucleate, grow, and finally connect. Therefore, breaking, dimples, and tearing edges can be inspected. Figure 14c shows the fracture morphology of AA6061/5 vol.\% N-SiCp composites sintered at $600{ }^{\circ} \mathrm{C}$. It can be discovered that there are many smaller dimples on the fracture surface. This is mainly due to the agglomeration of $\mathrm{N}-\mathrm{SiC}$ in the localized area and the $\mathrm{SiC}$ will be pulled out during the stretching process.

\subsection{Research on Wear Resistance}

\subsubsection{Effect of Volume Fraction of SiCp on Friction and Wear Properties}

Figure 15 shows that the wear rate of the AA6061/N-SiCp composite decreases gradually with the increase in the volume fraction of the N-SiC particles. When N-SiCp increases from 3 vol.\% to $15 \mathrm{vol} . \%$, the wear rate decreases from $0.55 \times 10^{-5} \mathrm{~g} / \mathrm{m}$ to $0.1 \times 10^{-5} \mathrm{~g} / \mathrm{m}$, indicating the wear resistance is improved. This is consistent with the conclusions reported by Zhang et al. [36], who studied the dry sliding friction and wear properties of AA2009/20 vol\% SiCp. 


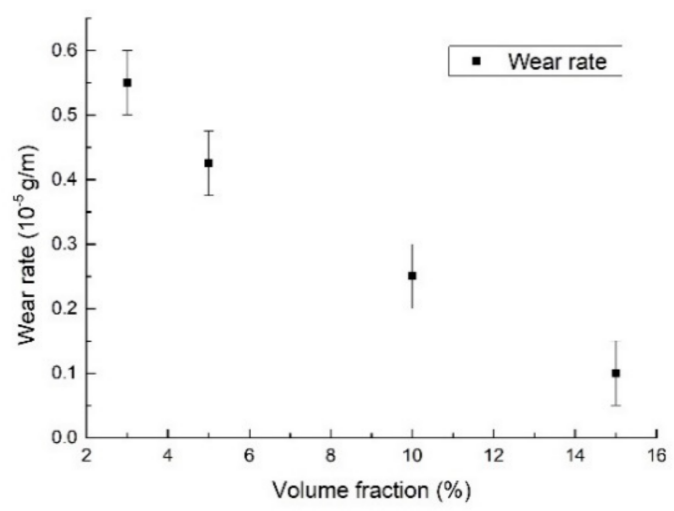

Figure 15. Effect of N-SiCp volume fraction on the wear rate of the composite under $4.5 \mathrm{GPa}$ and $550{ }^{\circ} \mathrm{C}$.

Figure 16 shows the friction and wear morphology of AA6061/N-SiCp composites with different content. For AA6061/3 vol.\% N-SiCp in Figure 16a, the wear model of the composite is mainly abrasive wear and slight adhesive wear. There are many furrows with different depths on the surface of the sample. The reinforcement effect of $\mathrm{SiC}$ is not obvious at the low content of N-SiC. During the wear process, the surface temperature increases, and the Al matrix softens. Under the friction of the grinding disc, the surface layer plastically deforms. Due to the intermolecular force, the Al substrate is cold welded to the surface of the grinding disc. Under the effect of shear stress, the welded joint is sheared and adhered to the surface of the grinding disc, causing the formation of a peeling block. As the friction and wear process progresses, the adhered $\mathrm{Al}$ matrix is detached from the surface and forms abrasive grains. Under the effect of the normal load or the forward load of the grinding disc, the $\mathrm{Al}$ substrate is cut and the surface is shaped, forming a large number of furrows. For AA6061/5 vol.\% $\mathrm{N}-\mathrm{SiCp}$, as shown in Figure 16b, the wear form is mainly abrasive wear and adhesive wear. The furrow depth becomes shallow, but the area of the peeling block formed by adhesive wear becomes large. Figure 16c shows the wear morphology of the AA6061/10 vol.\% N-SiCp composite. Generally, a greater hardness of the composite surface means better resistance to deformation, and smaller wear rate (only $0.25 \times 10^{-5} \mathrm{~g} / \mathrm{m}$ for AA6061/10 vol.\% N-SiCp composite). It can be viewed that the number of surface furrows is small, and the wear mechanism is mainly stripping wear. For AA6061/10 vol.\% $\mathrm{N}-\mathrm{SiCp}$, there are obvious agglomeration phenomena in the microstructure, and defects such as agglomerated pores. Under the effect of tangential load and normal load, the grinding disc is deformed on the sub-surface of the $\mathrm{Al}$ matrix. Cracks are nucleated at the pore locations, and the cracks grow or propagate under the external load, which finally shear to the surface and form a peeling layer.

For AA6061/15 vol.\% N-SiCp, the wear rate is only $0.1 \times 10^{-5} \mathrm{~g} / \mathrm{m}$. In the meantime, the wear model exhibits mainly fatigue wear, as shown in Figure 16d. Slight scratches and fatigue cracks can be inspected on the surface. For the high content of AA6061/N-SiCp, the surface hardness is high. The periodic load during the wear process causes the subsurface layer to plastically deform, bulge, and generate fatigue cracks. The excessive interface will also reduce the bonding strength, and the convex portion will be crushed to form wear debris. At this time, the abrasive chips are mainly composite particles of N-SiCp and Al particles, and the roundness is good. It is different from the polygonal micro-SiC cutting into the $\mathrm{Al}$ substrate. The bonding of the $\mathrm{Al}$ substrate and the grinding disc is appropriate, resulting in the enhancement of the wear resistance. The AA6061/N-SiCp composites have a very small size of $\mathrm{N}-\mathrm{SiCp}$, and the surface damage is less after the formation of abrasive chips; therefore, it is suggested that the wear resistance is better. 


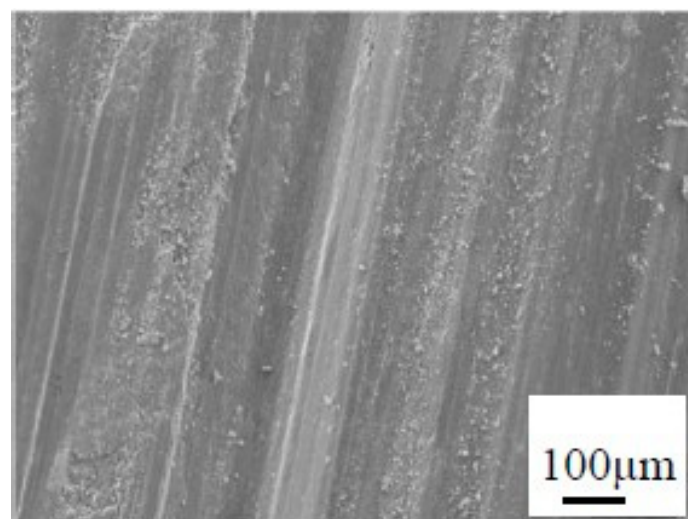

(a)

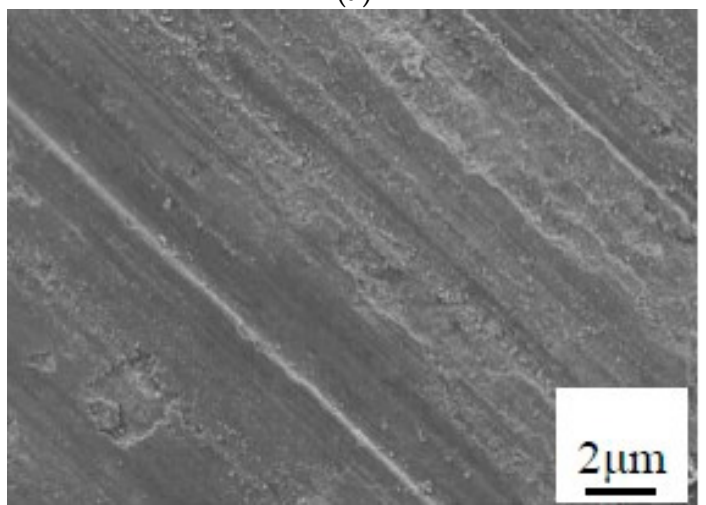

(c)

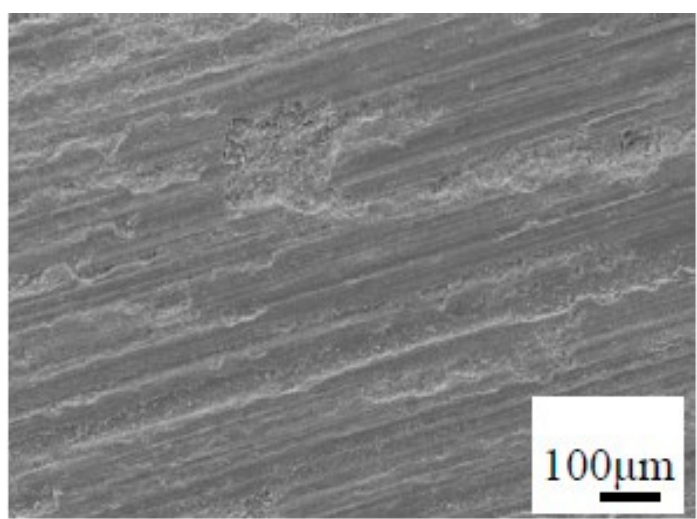

(b)

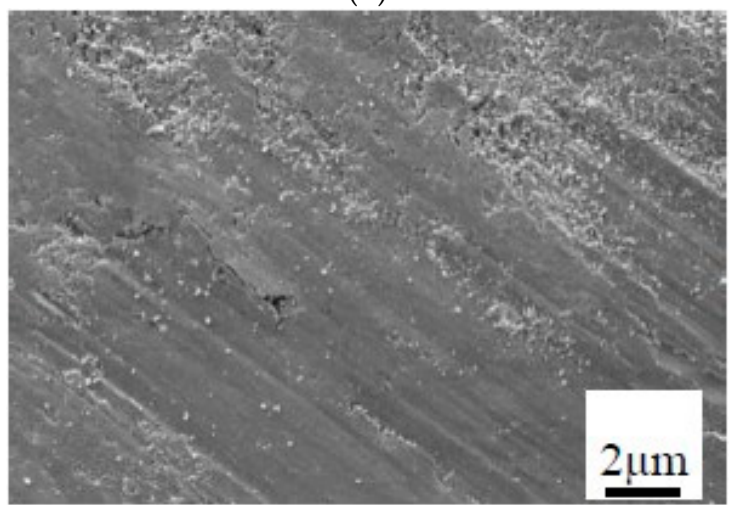

(d)

Figure 16. Wear morphology of $\mathrm{N}-\mathrm{SiCp} / \mathrm{Al}$ composite with different volume fraction under $4.5 \mathrm{GPa}$ and $550{ }^{\circ} \mathrm{C}$ with 3 (a), 5 (b), 10 (c), 15 (d) vol. \% N-SiCp.

\subsubsection{Effect of Sintering Temperature on Wear Resistance}

Figure 17 shows the temperature versus wear rate for AA6061/5 vol.\% N-SiCp. Figure 17 shows that increasing temperature will cause the wear rate to first decrease and then increase. Wear rate can reach up to the minimum at $600{ }^{\circ} \mathrm{C}, 0.225 \times 10^{-5} \mathrm{~g} / \mathrm{m}$. As the temperature increases, the hardness will increase, suggesting a better wear resistance of the sample. At $650{ }^{\circ} \mathrm{C}$, the wear rate increases again. This is mainly due to the $\mathrm{Al}_{4} \mathrm{C}_{3}$ brittle phase generated at the interface making the bond between the reinforcement and the $\mathrm{Al}$ matrix not tight at high temperature and is easily peeled off during the wear process.

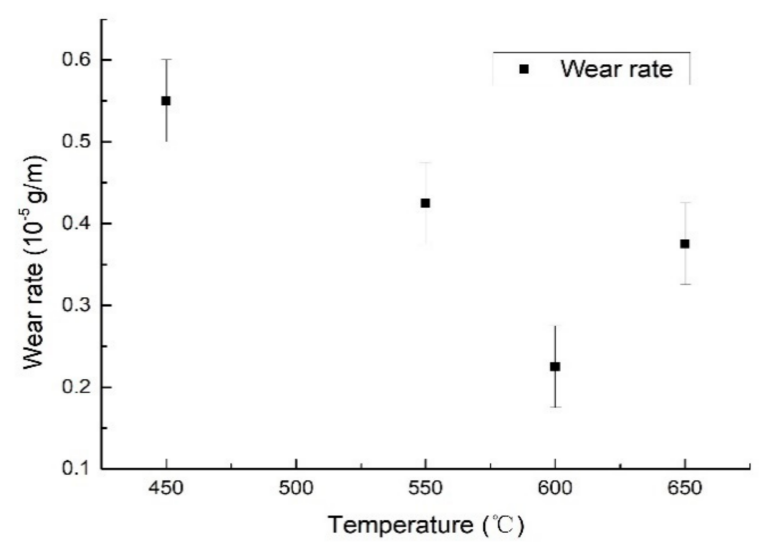

Figure 17. Effect of sintering temperature on the wear rate of AA6061/5 vol.\% N-SiCp under 4.5 GPa. 
Figure 18 shows the friction and wear morphology of AA6061/5 vol.\% N-SiCp sintered at 450, 550, 600 , and $650{ }^{\circ} \mathrm{C}$, respectively. A large number of exfoliated blocks appear on the surface in Figure 18a. At $450{ }^{\circ} \mathrm{C}$, the density and hardness are relatively low, and the surface has a large plastic deformation zone during the wear process. Additionally, the subsurface layer of the initiation deformation zone of cracks will spall. At $550^{\circ} \mathrm{C}$ in Figure 18b, the wear resistance is improved, and some shallow furrows and a small number of peeling pits can be found. It can be assumed that temperature increases the interfacial bonding strength and the hardness, so the wear rate is reduced. With the temperature further increasing up to $600^{\circ} \mathrm{C}$, the wear rate is just $0.22 \times 10^{-5} \mathrm{~g} / \mathrm{m}$. There are fewer small slim scratches and peeling blocks on the surfaces in Figure 18c than those in Figure 18a-d, which means the lightest damage. Meanwhile, a large number of $\mathrm{Al}$ particles exists in the microstructure, and the light interface reaction enhances the combination strength, resulting in the best wear resistance. Then, at $650{ }^{\circ} \mathrm{C}$, the wear rate increases, and wear resistance is reduced. A few deep furrows and spalling appear on the surface in Figure 18d. It might contribute to the $\mathrm{Al}_{4} \mathrm{C}_{3}$ phase produced at a high temperature. During the wear process, cracks are easily generated at the interface, causing the surface to peel off and abrasive grains. Combined with the hardness in Figure $12 \mathrm{~b}$ and wear rate in Figure 17, according to the role of $\mathrm{Al}_{4} \mathrm{C}_{3}$ in the composites, the wear rate of the composite possessing large hardness is small, indicating a good wear resistance. Therefore, it was also proven that the hardness was enhanced by the formation of the $\mathrm{Al}_{4} \mathrm{C}_{3}$ phase, resulting from the increment of wear rate.

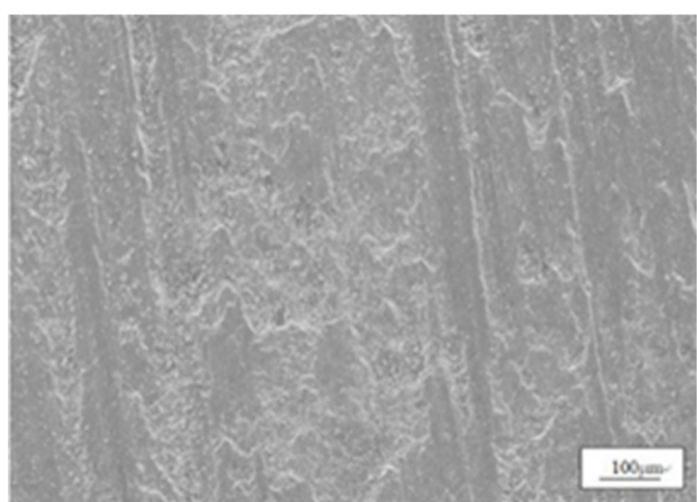

(a)

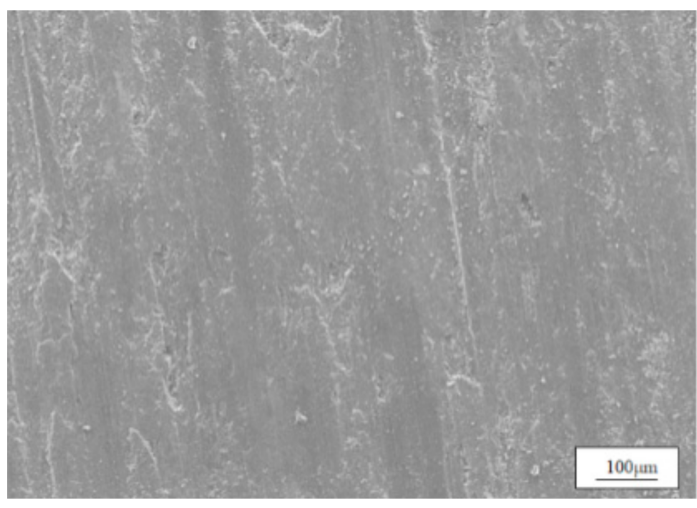

(c)

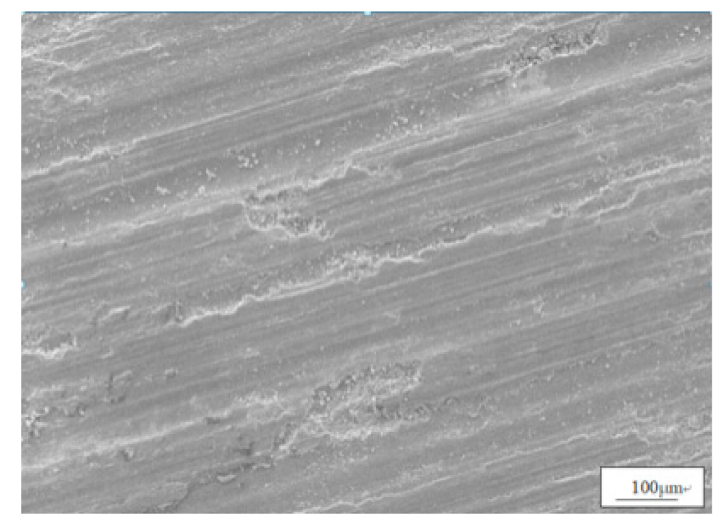

(b)

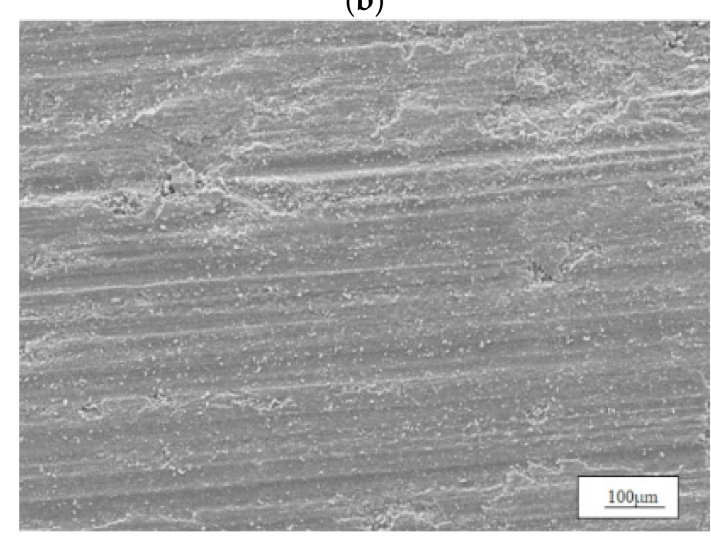

(d)

Figure 18. Wear morphology of AA6061/5 vol.\% N-SiCp sintered at: 450 (a), 550 (b), 600 (c), 650 (d) ${ }^{\circ} \mathrm{C}$.

\section{Conclusions}

This paper mainly studies the microstructure and properties of AA6061/N-SiCp composites. The main conclusions are as follows:

1. For AA6061/1 vol.\% N-SiCp and AA6061/3 vol.\% N-SiCp, there is almost no agglomeration, and the Al particles become irregular. Higher volume fraction will lead to a thicker $\mathrm{N}-\mathrm{SiC}$ layer 
around the $\mathrm{Al}$ particles. The rod-like particles appeared at the junction of the two particles. The $\mathrm{Al}_{4} \mathrm{C}_{3}$ phase was not detected for AA6061/1 vol. $\% \mathrm{~N}-\mathrm{SiCp}$ and AA6061/3 vol.\% N-SiCp. The increase in temperature has no significant effect on the agglomeration of N-SiCp, but the higher temperature can generate the better plastic flow of the Al matrix, the filling of the spheroidized pores, and the larger number of small-sized $\mathrm{Al}$ particles. The $\mathrm{Al}_{4} \mathrm{C}_{3}$ phase begins to appear at the interface at $550{ }^{\circ} \mathrm{C}$. As the temperature increases, the $\mathrm{Al}_{4} \mathrm{C}_{3}$ phase distribution at the interface becomes dense.

2. The density of the composites decreases with the increment of the volume fraction of N-SiC and increases with the augment in sintering temperature.

3. The hardness and wear property first increase and then decrease as the temperature increases. The hardness reaches up to $52 \mathrm{HRA}$, and the wear rate is just $1.0 \times 10^{-6} \mathrm{~g} / \mathrm{m}$ at $600^{\circ} \mathrm{C}$. The wear mechanism is mainly composed of abrasive wear and adhesive wear.

Author Contributions: Data curation, Z.C.; Funding acquisition, Y.W.; Supervision, L.X.; Visualization, G.M.; Writing - original draft, E.Y.; Writing — review and editing, C.L. All authors have read and agreed to the published version of the manuscript.

Funding: This work was supported by Research Foundation of China University of Petroleum-Beijing at Karamay, grant numbers XQZX20200016, XQZX20200019 and Science and Technology Plan of Karamay, grant number XQZX20200036.

Conflicts of Interest: The authors declare no conflict of interest.

\section{References}

1. Çinici, $\mathrm{H}$. Investigation of mechanical properties of $\mathrm{B}_{4} \mathrm{C} / \mathrm{SiC}_{\mathrm{A}} \mathrm{Al}_{2} \mathrm{O}_{3}$ particle reinforced $\mathrm{Al} 2024$ hybrid composites. Mater. Res. Express 2019, 6, 096535. [CrossRef]

2. Yang, J.; Long, L.; Li, Y.; Tian, Y.; Wang, J.; Zhang, K. Effect of sintering temperature on wear resistance of Al-Si-based composites reinforced by SiCp. Heat Treat. Met. 2015, 8, 110-113.

3. Hekner, B.; Myalski, J.; Valle, N. Friction and wear behavior of Al-SiC (n) hybrid composites with carbon addition. Compos. Part B Eng. 2017, 108, 291-300. [CrossRef]

4. Chen, X.; Xie, R.; Lai, Z.; Liu, L.; Yan, J.; Zou, G. Interfacial Structure and Formation Mechanism of Ultrasonic-assisted Brazed Joint of SiC Ceramics with Al 12Si Filler Metals in Air. J. Mater. Sci. Technol. 2017, 33, 492-498. [CrossRef]

5. Amouri, K.; Kazemi, S.; Momeni, A.; Kazazi, M. Microstructure and mechanical properties of Al-nano/micro $\mathrm{SiC}$ composites produced by stir casting technique. Mater. Sci. Eng. A 2016, 674, 569-578. [CrossRef]

6. Jiang, J.; Wang, Y. Microstructure and mechanical properties of the rheoformed cylindrical part of 7075 aluminum matrix composite reinforced with nano-sized SiC particles. Mater. Des. 2015, 79, 32-41. [CrossRef]

7. Jiang, J.; Chen, G.; Wang, Y. Compression Mechanical Behaviour of 7075 Aluminium Matrix Composite Reinforced with Nano-sized SiC Particles in Semisolid State. J. Mater. Sci. Technol. 2016, 32, 1197-1203. [CrossRef]

8. Sun, C.; Song, M.; Wang, Z.; He, Y. Effect of Particle Size on the Microstructures and Mechanical Properties of SiC-Reinforced Pure Aluminum Composites. J. Mater. Eng. Perform. 2010, 20, 1606-1612. [CrossRef]

9. Liu, S.Y.; Li, W.Z.; Jia, X.Y. Preparation and properties of nano-sized SiC particles reinforced AZ91D magnesium matrix composites. Rare Met. Mater. Eng. 2010, 1, 134-138.

10. Liu, S.; Li, W. Friction and Wear Properties of Nano-Sized SiC Particles Reinforced AZ91D Composites. Spec. Cast. Nonferrous Alloy 2012, 10, 935-939.

11. Gao, H.X.; Wang, H.L.; Yang, D. Study on single nanoparticles and nano/micro SiC particles reinforced aluminum composites. Powder Metall. Technol. 2016, 1, 11-15.

12. Zhang, L. The Fabrication, Microstructures and Mechanical Properties of Micro-And Nano-Sized SiCp/Al2014 Composites. Master's Thesis, Jilin University, Jilin, China, 2015.

13. El-Kady, O.; Fathy, A. Effect of $\mathrm{SiC}$ particle size on the physical and mechanical properties of extruded $\mathrm{Al}$ matrix nanocomposites. Mater. Des. 2014, 54, 348-353. [CrossRef]

14. Wang, H.; Xie, J.; Hao, S. Effort of $\mathrm{SiC}$ particle size on the microstructures and properties of aluminum matrix composites. Powder Metall. Technol. 2013, 31, 344-348. 
15. Li, C.Y.; Wang, Y.S.; Xu, Y.; Liu, Y.; Lu, N.N.; Mi, G.F. Microstructure and Mechanical Property of Compact Graphite/6061Al Composite Prepared by Ultra-High Pressure Sintering. Appl. Sci. 2020, 10, 5107. [CrossRef]

16. Xiang, Z.; Nie, J.; Wei, S.; Zuo, T. Mechanical Properties of $15 \%$ SiCp/6061Al Composites with Heat Treatment and Different SiCp Sizes. Chin. J. Rare Met. 2015, 39, 998-1003.

17. Nirala, A.; Soren, S.; Kumar, N.; Dwivedi, V.; Kaushal, D. A comprehensive review on stir cast Al-SiC composite. Mater. Today: Proc. 2020, 21, 1610-1614. [CrossRef]

18. Schilling, J.S. The use of high pressure in basic and materials science. J. Phys. Chem. Solids 1998, 59, 553-568. [CrossRef]

19. Chang, R.; Rhodes, C.G. High-Pressure Hot-Pressing of Uranium Carbide Powders and Mechanism of Sintering of Refractory Bodies. J. Am. Ceram. Soc. 1962, 45, 379-382. [CrossRef]

20. Li, D.C. Study on SIMA Semi-Solid Forming of Aluminum Alloy and Its Particles Reinforced Composites. Master's Thesis, Jilin University, Jilin, China, 2009.

21. Clyne, T.W.; Withers, P. An Introduction to Metal Matrix Composite; Cambridge University Press: Cambridge, UK, 1993.

22. Van Swygenhoven, H.; Derlet, P.M.; Frøseth, A.G. Nucleation and propagation of dislocations in nanocry stalline fcc metals. Acta Mater. 2006, 54, 1975-1983. [CrossRef]

23. Simon, F.; Glatzel, G. Bemerkungen zur Schmelzdruckkurve. J. Inorg. General Chem. 1929, 178, $309-312$. [CrossRef]

24. Yuan, G.S.; Li, M.K.; Wang, Z.Y. Effect of sintering temperature on mechanical properties and microstructure of SiCp/6061Al composite. Hot Work Technol. 2017, 46, 123-125.

25. Li, H.Y.; Ouyang, X.; Zhao, S.X. Microstructure and properties of nano-SiC/Al composites fabricated by SPS. Min. Metall. Eng. 2016, 36, 113-116.

26. Xie, M.L.; Luo, D.L.; Xian, X.B. Nano-SiC ceramic sintering at ultra-high pressure and high temperature. J. Inorg. Mater. 2008, 39, 811-814. [CrossRef]

27. Jin, P.; Xiao, B.L.; Wang, Q.Z. Effect of hot pressing temperature on microstructure and mechanical properties of $\mathrm{SiC}$ particle reinforced aluminum matrix composites. Acta Metall. Sin. 2011, 47, 298-304.

28. Ardakani, M.R.K.; Khorsand, S. Application of compocasting and cross accumulative roll bonding processes for manufacturing high-strength, highly uniform and ultra-fine structured Al/SiCp nanocomposite. Mater. Sci. Eng. A 2014, 592, 121-127. [CrossRef]

29. Hua, Q.Q. Preparation of power metallurgy submicron $\mathrm{SiC}$ particles reinforced $\mathrm{Al}$ based composites and mechanical properties. Spec. Cast. Nonferrous Alloys 2017, 34, 411-414.

30. Tian, X.F.; Xiao, B.L.; Fan, Z. Mechanical properties of nano-SiCp reinforced 2024 aluminum composite. Chin. J. Rare Met. 2005, 29, 521-525.

31. Hao, S.M.; Xie, P.; Hang, W. Effects of size of micrometer SiC particles on tensile properties and strengthening mechanism of SiCp reinforced aluminum matrix composites. Trans. Mater. Heat Treat. 2014, 35, 13-18.

32. Sivakumar, G.; Ananthi, V.; Ramanathan, S. Production and mechanical properties of nano SiC particle reinforced Ti-6Al-4V matrix composite. Trans. Nonferrous Met. Soc. China 2017, 27, 82-90. [CrossRef]

33. Li, B.L. Synthesis Microstructure and Properties of Nano-SiCp/AlComposite. Master's Thesis, Harbin Institute of Technology, Harbin, China, 2013.

34. Li, Y. Structure, Performance and Hot Deformation of Nano-Sized SiCp/108Al Composite. Master's Thesis, Henan University of Science and Technology, Henan, China, 2017.

35. Riquelme, A.; Rodrigo, P.; Escalera-Rodríguez, M.D.; Rams, J. Characterisation and mechanical properties of $\mathrm{Al} / \mathrm{SiC}$ metal matrix composite coatings formed on ZE41 magnesium alloys by laser cladding. Results Phys. 2019, 13, 102160. [CrossRef]

36. Zhang, Z.F.; Zhang, L.C.; Mai, Y.-W. Particle effects on friction and wear of aluminium matrix composites. J. Mater. Sci. 1995, 30, 5999-6004. [CrossRef]

Publisher's Note: MDPI stays neutral with regard to jurisdictional claims in published maps and institutional affiliations. 